\title{
A Macroeconomic Framework for Growth and Employment Generation
}

\author{
Ricardo Gottschalk
}

\begin{abstract}
1 Introduction
Many low-income countries have achieved macroeconomic stability in the recent past, and are currently experiencing moderate, in some cases fast, economic growth. In this new context, these countries are facing the challenge of how to accelerate growth and how to macro-manage the economy to ensure that faster growth can be maintained over time. A related challenge is how to strive for a growth pattern that is pro-employment creation, so that it is more inclusive and thus truly sustainable.
\end{abstract}

Recent work has shown that low-income countries have macroeconomic frameworks that have been designed to support mainly macroeconomic stability, with very few elements to support growth directly (IEO 2007; Gottschalk 2005, 2008). These frameworks include tight monetary policy linked to too low inflation targets, fiscal policy that fails to support capital expenditure for supply capacity expansion, and lack of an exchange rate regime that clearly prioritises export competitiveness. The main problem with these policies is that they constrain countries' ability to support fast growth. They are clearly inappropriate, particularly at a time when low-income countries seek faster growth to meet the Millennium Development Goals (MDGs). This IDS Bulletin article proposes a macroeconomic framework that is better aligned with low-income countries' quest for faster growth, a framework that has internal coherence and that does not constrain structural or other policies for growth and employment creation. ${ }^{1}$

\begin{abstract}
2 What might a macroeconomic framework that supports growth and employment creation look like? ${ }^{2}$

A first answer to this question is that there is not such a ready-made macroeconomic framework that can be applied universally. First, a macroeconomic framework for growth and employment generation should be tailored to country-specific features and challenges. Second, it should reflect the external environment the country faces at the time of design and implementation.
\end{abstract}

A country facing high macroeconomic instability may wish for a macroeconomic framework that has sufficient flexibility to address macroeconomic issues in a dynamic way. This entails initial emphasis on restoring macroeconomic stability. However, from the outset, the strategy should combine policy measures for stability with the adoption of a set of other measures to address economic recovery directly. For example, a country facing very high inflation - say over 50 per cent annual inflation - and large current account deficit, may have a macroeconomic framework in place that supports a strong fiscal adjustment and exchange rate depreciation, to bring inflation down to more acceptable levels and increase the country's level of external competitiveness. However, the fiscal adjustment should ensure that a minimum level of public capital expenditure is maintained so that the country is able to restore growth more rapidly and in a sustainable way.

Monetary tightening must certainly constitute a further component in the stabilisation strategy, but it 
should not be indiscriminate. It should take into account the impacts high interest rates may have on a country's domestic debt and on the availability and cost of capital, especially when the domestic financial system is bank-dominated. A measured monetary policy response to macroeconomic instability is important to provide the private sector, especially the export-oriented segments, sufficient financing conditions to respond to the new set of macroeconomic policies and incentives, including changes in relative prices.

However, the facts that macroeconomic indicators of low-income countries have improved significantly since the late 1990s and early 2000s, and that external financing conditions have much improved as well, imply that a macroeconomic framework for these countries should reflect these developments today. $A$ key feature of a framework in this new environment is to have growth playing a central role.

Growth should have a central place in a macroeconomic framework, first because it is the fastest and most effective way to tackle large-scale poverty, which is the sort of poverty facing lowincome countries. Second, because growth can generate employment, and to the extent it is possible to pursue a pro-employment growth pattern, the employment-generation effect can be large. Third, growth makes availability of public resources for poverty reduction to expand more rapidly in absolute terms. Of course, the speed to which poverty can be reduced (the elasticity of poverty reduction to growth) depends on a country's initial income and assets' distribution and the pattern of growth that takes place - pro-poor or anti-poor. Attempts to shift a growth pattern from anti-poor to pro-poor growth or to reinforce a pro-poor pattern should focus on a variety of structural and sectoral policies aimed at tackling the sources of anti-poor growth. ${ }^{3}$

The core of a macroeconomic policy framework monetary, fiscal and exchange rate policies - should in turn be designed with the principal aim to support growth directly. The focus should be on growth because this is a policy goal easier to target through monetary, fiscal and exchange rate policy instruments. Their effects on employment generation and poverty exist, but, except for fiscal policy, these tend to take place through multiple and indirect channels, making it difficult to tailor such policies to these other policy goals directly.
In addition, these policies should have flexibility, which they lack today due to their narrow focus on stability and the existence of an array of stringent rules and targets they follow to ensure stability is achieved and maintained. Flexibility is important for low-income countries, first to enable them to deal appropriately with external shocks and macroeconomic volatility, which have major effects on poverty, employment and growth; second, to give countries the space to formulate and implement policies to effectively support growth. Flexibility can be construed in a broad sense, to include choice of instruments, possibility of shifting from one policy objective to another in response to changing circumstances, avoidance of stringent targets, and space to deal with external shocks.

A macroeconomic framework centred on growth, nonetheless, should be anchored in sensible macroeconomic management. In fast growing developing economies undergoing structural changes, the framework may allow for the emergence of certain macroeconomic imbalances, provided these are kept within reasonable boundaries. For example, a current account deficit may take place, provided it is investment-led and hence reversible in the long term, and do not take the country to unsustainable debt levels. Inflation may rise but as a result of external shocks, domestic supply shocks and growth-led bottlenecks, which can be addressed through targeted policy action. Moreover, the boundaries within which imbalances may be permitted should not be set the same across countries. Instead, these should vary according to each country's macroeconomic history and characteristics. What should be avoided is that growth becomes entirely subordinated and constrained by the quest for macroeconomic stability, narrowly defined. That is, excessive focus on very low inflation and fiscal balance, which can taper off growth.

Although macroeconomic frameworks to support a growth and employment generation strategy should be allowed to vary from country to country, a common set of elements can be expected to feature in each of the core macroeconomic policies monetary, fiscal and the exchange rate policies. Moreover, given that each of these should support growth directly, it is important that a macroeconomic framework clearly establishes targets for growth and identifies financing sources to support the targets. What follows provides a 


\section{Figure 1 Inter-linkages between macroeconomic policies, growth and poverty}

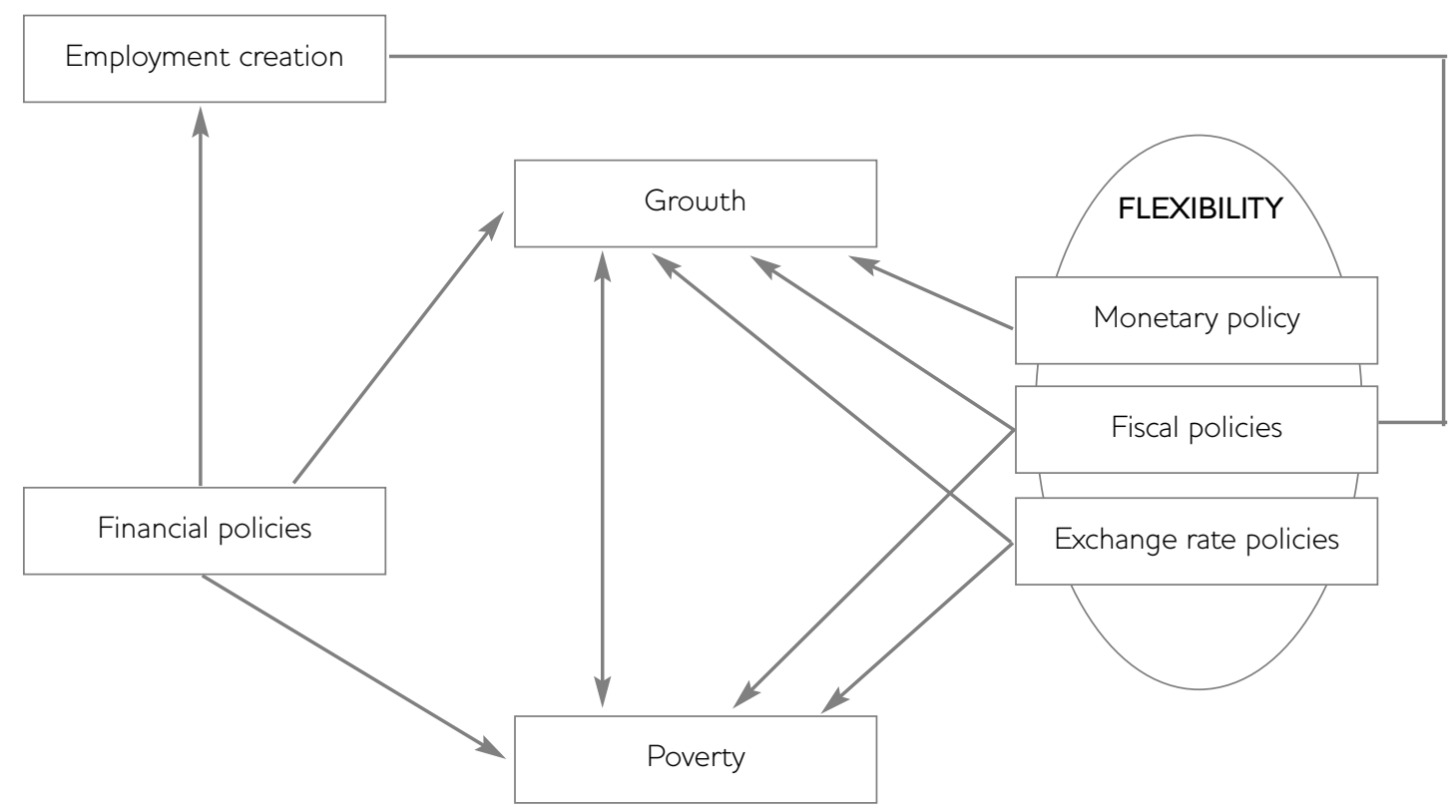

Source Author's elaboration.

template for a pro-growth macroeconomic framework, covering what growth targets it should have and what elements may be needed in monetary, fiscal and exchange rate policies to achieve these targets. Because the ability of the core macroeconomic policies to address employment creation and poverty reduction directly admittedly is limited, this article in addition briefly discusses the need to have financial policies to support these policy goals directly, a discussion that is vital in light of the lack of pro-development focus in ongoing financial sector reforms in developing countries.

Figure 1 depicts the inter-linkages between the various macroeconomic policies, growth, employment and poverty reduction, and also shows the incorporation of flexibility, a critical dimension cutting across different policy areas.

\subsection{The growth targets}

To garner support for and maintain focus on growth, it is important that clear growth targets are established. These should be fully consistent with the other components of a country's growth and employment generation strategy, and with available and potential sources of financing. Moreover, it should look feasible in light of the country's growth track record in the recent past, though not excessively tight to it. Furthermore, a range for growth targets should be established and linked to alternative scenarios for the various financing sources. It is also desirable that the growth targets are linked to the Millennium Development Goals (MDGs), but this should be only so where feasible, so that the overall strategy is realistic and credible.

The various financing sources for the targeted growth must be clearly identified. These should include fiscal and private sources.

The two main sources within the fiscal component external financing and domestic tax revenues should be provided with baseline and alternative scenarios. The upper range of these scenarios should include optimistic assumptions regarding future flows of external finance and revenues. The assumptions underlying the various scenarios should be made explicit. For example, in building projections for aid flows (a main external financing source), one must show how much weight is assigned to past trend in aid flows, and how much to promises of future flows by donors. In the case of tax revenue sources, it 
should be made clear by how much new tax efforts and tax sources are expected to contribute to increases in projected revenues, and how realistic assumptions underlying projections are.

In relation to private financing sources, although the national accounts provide information on their magnitude, which in turn can serve as a basis for macroeconomic projections, it would be desirable that a qualitative analysis is conducted as well. It should be on how private resources could be better leveraged for growth. Special attention should be given to those resources amassed by domestic institutional investors. These resources have become increasingly significant in a number of low-income countries in recent years, but, typically, end up invested in domestic government securities due to lack of investment alternatives.

What has been outlined above can be considered a financing approach to growth. This approach can be complemented in two ways.

First, a plan containing measures to increase overall economic efficiency should be laid down. This should include investment in key infrastructure projects, whose spill-over effects are expected to reduce systemic costs and raise productivity across different sectors of the economy. These investment plans should be an integral part of budgetary planning, thereby helping increase coherence between the various components of the macroeconomic framework - in this case, coherence between growth targets and fiscal policy.

Second, measures should be included to reduce growth volatility, because it can affect long-term growth through uncertainty it creates. The main measures to reduce growth volatility should be embedded in the fiscal component - for example, these could take the form of counter-cyclical fiscal rules to smooth out aggregate demand, although the monetary and exchange rate policy components also can be expected to play a role in minimising this type of volatility.

The inclusion of a growth component in an explicit, target-linked way in a macroeconomic framework is seen as important to ensure a coherent framework in which growth helps mould the other components of the framework. However, it should be made clear that a focus on growth is not the same as having a fully fledged growth strategy. The latter, ideally developed in tandem with the macro-framework, includes a detailed analysis of the main drivers and constraints to growth, and specifies reforms and policy measures for a wide range of areas such as financial sector, infrastructure, skills, labour markets, and industrial and agricultural sectors. ${ }^{4}$ What is important is that the macroeconomic framework is fully consistent with this strategy, and that clear links between the two can be established.

\subsection{Monetary policy}

A monetary framework that is broadly consistent with growth should avoid a narrow focus on price stability. There is a need that it supports broader policy objectives, including the exchange rate policy, increase in international reserves, output growth and employment.

Targets for inflation should not be set at too low a level. They may be inappropriate particularly for lowincome countries with narrow economic structure, various supply-side constraints and limited access to hedging instruments, features that contribute to greater domestic price volatility. Prices therefore should be allowed to vary within a wider range before conventional demand management policies are called for.

It is an issue of debate what should be the maximum level of inflation permitted, in order to avoid that too high inflation undermines growth. The literature suggests a range of possible inflation levels - from around 7-11 per cent level, to 15 per cent to 30 or even 40 per cent. ${ }^{5} \mathrm{~A}$ related issue is that inflation can be bad not just for growth but for a country's international competitiveness and for poverty. In light of this, it is appropriate that policy decision-making on what may be considered an acceptable inflation level takes all these three aspects into account. But because what matters is not just inflation level but its dynamics and the risk that it becomes entrenched, it is important that the decision-making process on when and how to react to inflation is informed by the country's own inflation history, and its structural and institutional characteristics, including level of economic diversification, degree of trade openness and domestic markets' integration, level of monetisation of the economy, size and strength of organised labour markets, degree of indexation in the economy, and coverage and quality of consumer price indexes. For example, a country 
with a very narrow economic base, poorly integrated product markets, low degree of monetisation and lacking price indexation mechanisms will be more susceptible to external shocks and inflation will tend to be more volatile. However, shock-induced high inflation will tend to be localised and revert to lower levels once the shock effects die out. In this case, demand-management policies to combat inflation will be both ineffective and unnecessary.

It might be advisable that a system of comprehensive inflation analysis is in place to be drawn upon when an inflation surge takes place, and that conventional demand management action is adopted not when inflation hits a specific threshold, but when the diagnosis clearly indicates that inflation has shifted from a localised to a generalised phenomenon. Typically, the latter happens as a result of economic over-heating, and it cannot be tackled through topical actions alone. Thus, an increase in inflation should be addressed through the use of conventional instruments not when it hits a specific threshold, as it may happen as a result of a supply shock whose effects may die out and inflation reverse, but when it is broad based.

The effectiveness in the use of conventional instruments, such as interest rates should be carefully assessed - and in cases in which effectiveness is judged limited and costs too high, alternative instruments should be considered instead. Limited effectiveness of interest rates may be associated with an economy where credit is not demand-led but rationed and time for the economy to respond to interest rates takes too long. Costs, in turn, may be associated with the size and maturity of domestic debt. If the government debt is large and most of it is of short maturity, then short-term interest rates to contain demand may imply large increases in domestic public debt, if used for too long.

Today, the macroeconomic challenge that a lowincome country is likely to face is that of excess liquidity, as a consequence of export windfalls and/or persistent aid inflows, and government's systematic interventions in the foreign exchange market to avoid exchange rate appreciation. In these cases, an appropriate policy response could be a combination of an increase in reserve requirements and sterilisation. The goal should be to permit a level of liquidity that supports the smooth functioning of the economic activities and thus growth, while avoiding liquidity becoming excessive. At the same time, monetary policy should be attentive to developments in two key external sector variables - level of reserves because high reserves can be used in times of shocks to reduce exchange rate and demand volatility, and the exchange rate because it is essential to maintain export competitiveness, an important source of growth.

\subsection{Fiscal policy}

An underlying feature of the various elements proposed above for the monetary framework is flexibility - for example, in how to decide what level of inflation may be deemed acceptable, or when to switch from topical to demand management actions to combat inflation, or what policy goal to focus on.

Fiscal policy should equally be designed in ways that flexibility exists to deal with different, sometimes unexpected, economic situations. This implies the following.

First, stringent fiscal criteria that usually come packaged within stability pacts, such as the WAEMU Convergence, Stability, Growth and Solidarity Pact, should be avoided - as it takes flexibility away from fiscal framework needed to adapt to specific circumstances and needs. Flexibility should be institutionalised - for example through incorporation in the fiscal framework of counter-cyclical fiscal rules and mechanisms to be activated to deal with macroeconomic volatility and external shocks, which tend to affect the poorest the hardest. These mechanisms could include permanent safety nets, which would be in place when a shock hits and therefore could be quickly activated. If permanent, safety nets could have a budget that operates counter-cyclically. Safety nets are important for meeting at least two policy objectives: protecting the poor who lack self-insurance mechanisms to draw on when a shock hits, and to smooth out aggregate demand, so that growth becomes less volatile. While safety nets are crucial for low-income countries with very limited means to deal with shocks, countries graduating from low-income to middle-income levels could strive to have in place a social protection system with universal coverage.

Second, fiscal policy should support both growth and employment generation directly. Given that povertyrelated spending has been prioritised in recent years in detriment to pro-growth spending, ${ }^{7}$ the latter 
should be given particular attention from now onwards. It is important that pro-poor spending is conducive to job creation, and that pro-growth spending focuses on infrastructure projects that support intensive job-generation activities. Measures that can be undertaken to ensure that a minimum pro-growth spending is guaranteed in face of budgetary constraints may include setting a minimum threshold for this type of expenditure, which traditionally in times of budget tightening tends to be disproportionately reduced. Moreover specific funding sources outside the tax revenue pot could be identified for pro-growth spending, such as proceedings from privatisation, and unexpected additional financing, such as sudden aid increases or export windfalls from state-owned companies.

Third, to further support growth, a fiscal framework should have instruments to mobilise capital, including the use of tax incentives for new investment and production, to support supply capacity expansion.

Fourth, the conduct of fiscal policy should be anchored in the principle of fiscal sustainability. This implies that persistently large fiscal deficits should be avoided, and plans to bring it to balance in the long term should be clearly devised. However, in line with the need for a fiscal framework to have countercyclical instruments to help reduce macroeconomic volatility, it should allow for the widening of the fiscal deficit when needed. So the long-term trend should be of a declining deficit, but room should be given for the deficit to vary around the trend.

Low-income countries have invariably low government revenue levels. Therefore, to achieve fiscal balance, the focus should be on increased revenues rather than expenditure cuts. In order to increase revenues, tax measures and instruments should be clearly identified. As part of tax-raising revenue efforts, it is important to try to widen the tax base. However, this should not be done through strengthening the VAT alone. VAT is regressive and should therefore be one among various tax instruments. The combination of the use of various tax instruments should result in an increased share of direct (rather than indirect) taxes in total revenues.

\subsection{Exchange rate policy}

Exchange rate policy should aim at a competitive exchange rate to support both the export sector and import-competing industries.
Exports are an important source of growth and foreign exchange earnings. In addition, exports can help create jobs - in some low-income Asian countries they originate from labour-intensive manufacturing, although this is not always the case in many sub-Saharan African countries exports are based on extractive activities that generate few jobs. Nonetheless, the import-competing industries, which also benefit from a competitive exchange rate, tend to have a higher employment-output ratio.

A competitive exchange rate should be pursued within a managed exchange rate regime, which allows for some exchange rate flexibility while maintaining competitiveness. Flexibility is important as a hedging mechanism against terms-of-trade and other external shocks. At the same time, the regime should be a managed one because a fully flexible regime may not be advisable for low-income countries. Unlike developed countries, they may suffer from a particularly high degree of exchange rate volatility due to their relatively small foreign exchange and derivative markets, and unstable foreign exchange earnings.

Both excessive exchange rate depreciation and appreciation should be avoided.

Excessive depreciation can cause inflationary pressures and major shifts in the currency asset-liability balances of the financial and other sectors of the economy. It is possible to find a number of countries where mismatches, especially currency ones, are a serious problem. Mismatches can be especially harmful to countries witnessing a high degree of dollarisation, which is not an uncommon feature among low-income countries. This is due to the fact that these countries attract large aid flows as a proportion of their GDP, and permit dollardenominated bank accounts. The counterpart of these deposit liabilities is that banks tend to lend in US dollars to avoid currency mismatches. However, lending may be channelled not only to exporting firms but also to firms that generate revenues in domestic currency. This leaves banks vulnerable due to the credit risk that may arise from large and abrupt exchange rate adjustments, as it can affect the borrower's ability to honour their debt. The major challenge for these countries is to be able to find ways to de-dollarise the economy as economic growth and financial development takes place, and as they become less dependent on aid flows. 
In turn, excessive currency appreciation should be avoided to prevent loss of external competitiveness, which may undermine export activities and cause serious difficulties for import-competitive industries. Current export booms and increased foreign aid have put pressures on countries' exchange rates towards appreciation, which if left unchecked can lead to currency overvaluation and sharp deterioration of the current account. In this case, interventions in the foreign exchange markets to slow down or avoid currency appreciation are required.

However, intervention in foreign exchange markets to purchase foreign currency implies accumulation of international reserves. Reserve accumulation may be desirable in helping the country achieve a level of reserves that can serve as a cushion when the country faces a major external shock. Even in relatively normal times, reserves enable the Central Bank to make effective interventions in foreign exchange markets to reduce exchange rate volatility. But there is also the downside. The main one is that continued, large interventions lead to excessive expansion of liquidity; a major challenge for monetary policy. The typical response, in the form of sterilisation, can be fiscally costly and difficult for monetary authorities to manage in the light of limited instruments at their disposal. Although holding international reserves may be costly, costs can be reduced if countries were able to agree on alternative insurance schemes, such as regional pooling of international reserves.

\section{Financial policies: going the wrong direction?}

Up to now, this article has proposed how three core macroeconomic policies - monetary, fiscal and exchange rate policies - may be designed to support growth directly. However, while it is possible to design monetary and exchange rate policies having growth as a direct policy goal, limited scope exists to design such policies to support employment generation or poverty reduction directly. The fiscal policy framework through its tax revenue and expenditure instruments makes it possible, but what may be attained through the use of these instruments is somewhat limited. We therefore complement our proposal through discussing the role financial policies (which are closely related to at least monetary and exchange rate policies) may have in employment generation and poverty reduction.

Most low-income countries that have formulated poverty reduction strategies in the recent past have strongly emphasised their commitment to undertaking financial reforms, seen as necessary for the development of the financial sector and growth enhancement. These reforms include strengthening the banking system via privatisation, more competition, and improving prudential banking regulation and supervision, in line with the Basel core principles.

A fundamental problem in relation to the proposed financial reforms is that public and in particular development banks are closed down or privatised, directed credit is eliminated, and all possible types of credit provision are left to the discretion of private banks. However, in response to pressures to gain efficiency private banks have been closing their agencies in areas of lower population density, which tend to be the rural ones where the poor are concentrated. Moreover, they are expected to comply with capital requirements which are costly thereby driving them to take cost-saving measures which make it unattractive to lend to small customers. Furthermore, new banking regulation encourages the use of risk-based assessment systems both for capital allocation and credit provision, which are information intensive. This makes banks face constraints to expand credit to small businesses and the poor as it is hard to obtain historical data information on these customers, which banks need to feed their new assessment systems. With the drive away from public and development banks and directed credit, and towards risk-based assessment systems for credit, the overall trend will be of less, rather than more, credit to the poor - and the small and medium-sized enterprises, which are important employment-generating sources in low-income countries.

The result is that the financial sectors that are emerging in low-income countries lack the institutions, instruments and incentives to support a broad-based growth strategy. This is a missed opportunity, as financial systems could play a vital role in supporting a growth employment generation and poverty reduction strategy. It is essential that lowincome countries preserve part of their public banking system and their development banks where these still exist, so that these can leverage resources to support investment projects in basic infrastructure and job-generation activities, and provide credit to the poor to enhance their earning capacity. Where only private banks remain, it is important that directed credit policies are implemented to ensure the banking system still lends, and in significant proportions, to the SMEs and the poor. 


\section{Conclusion}

This article takes as a departure point the assertion that although low-income countries are striving for faster growth to meet the MDGs, their macroeconomic policy frameworks are designed to support mainly macroeconomic stability, with very few elements that support growth or employment creation directly. Given this, the article proposes an

\section{Notes}

1 The proposed framework is mainly for low-income countries with the following features: narrow economic base and large dependence on just one or very few commodity exports; recipient of aid flows and FDI and limited access to private portfolio capital flows; relatively low level of markets integration, limited formal labour markets and low degree of price indexation mechanisms; and bank dominated financial systems.

2 This draws on a variety of proposals for progrowth and pro-poor macroeconomic policies, put forward by a number of academics and UNbased officials. These include Gottschalk (2005), Saad Filho (2007), Weeks and McKinley (2007) and Vandermoortele (2004). Although these proposals share a fair degree of commonality, they differ in emphasis and level of detail.

\section{References}

Gottschalk, R. (2008) 'The Effectiveness of the Macroeconomic Frameworks of the PRSPs for Growth and Poverty Reduction', draft paper prepared for UNRISD, February

Gottschalk, R. (2005) 'The Macro Content of PRSPs: Assessing the Need for a More Flexible Macroeconomic Policy Framework', Development Policy Review 23.4: 419-42

Goudie, A. and Ladd, P. (1999) 'Economic Growth, Poverty and Inequality', Journal of International Development 11: 177-95

IEO (2007) The IMF and Aid to Sub-Saharan Africa, Independent Evaluation Office, IMF

Khan, M. and Senhadji, A. (2001) Threshold Effects in the Relationship Between Inflation and Growth, IMF Staff Papers 48.1

McKinley, T. (2004), 'MDG-Based PRSP's Need More Ambitious Economic Policies', UNDP, draft discussion paper alternative macroeconomic framework in which core macroeconomic policies support growth directly, and have sufficient flexibility, in terms of choice of instruments, targets and goals. The ultimate aims are to help low-income countries achieve faster economic growth, create jobs, reduce poverty, and protect the most vulnerable to macroeconomic volatility and shocks.

3 For a discussion on the interactions between different forms of inequality and growth, see Goudie and Ladd (1999) and Naschold (2002); for a discussion on distribution and different growth patterns, see White and Anderson (2001).

4 For a discussion of areas that may be important and thus included in a country-specific growth strategy, see Walton (2007).

5 See Khan and Senhadji (2001), who find that the threshold may be at 11-12 per cent for developing countries; and McKinley (2004) who argues that high inflation - above 40 per cent - may hurt the poor.

6 WAEMU stands for West African Economic and Monetary Union, formed of the following countries: Benin, Burkina Faso, Cote d'Ivoire, Guinea-Bissau, Mali, Niger, Senegal and Togo.

7 See, for example IEO (2007).

Naschold, F. (2002) Why Inequality Matters for Poverty, Inequality Briefing 2, March, ODI

Saad Filho, A. (2007) Economic Policies, MDGs and Poverty, Training Module 2, July, Monetary Policy, International Poverty Centre

Vandermoortele, J. (2004) The MDGs and Pro-Poor Policies: Related but Not Synonymous, International Poverty Centre Working Paper 3, November, UNDP

Walton, M. (2007) 'Issues for a Big Push on Research-based Policy Design for Growth', note prepared for DFID, 31 December, unpublished

Weeks, J. and McKinley, T. (2007) The Macroeconomic Implications of MDG-Based Strategies in SubSaharan Africa, Policy Research Brief, International Poverty Centre, 4 October

White, H. and Anderson, E. (2001) 'Growth Versus Distribution: Does the Pattern of Growth Matter?', Development Policy Review 19.3: 267-89 